\title{
An effective solid waste management system in Awka, Anambra State, Nigeria: a proffered solution of a well-articulated plan of attributes
}

\author{
A. U. Okonkwo \\ The Department of Environmental Management, Anambra State \\ University, Nigeria
}

\begin{abstract}
Awka, the capital of Anambra State of Nigeria is presently experiencing various forms of waste management problems and is more or less already in a state of visual devastation. Methods of solid waste management are grossly inadequate and this could be attributed to approaches, which are not all embracing. Solid waste management in Awka has experienced change from one management agency to another without yielding the desired results. The existing approaches have often treated solid waste disposal as independent from solid waste generation or density of the population generating the waste or the characteristics of the waste being generated. This paper is emphasizing that, for an effective waste management system; there should be a well-articulated plan of the various attributes of the system. The degree of effectiveness is measured by the volume of actually generated waste and the rate at which it is evacuated.
\end{abstract}

Keywords: generation, well-articulated, classification, attributes, waste management.

\section{Introduction}

Growing interest and attention have been paid to the analysis of environmental problems associated with rapid growth of urban centres in this part of the world. The environmental situation in the cities of Nigeria serves to illustrate the physical problems that are associated with the process of urban development in the country. Urbanization is known to attract increasing population and living standards. This in turn affect the quantity and characteristics of solid waste generated. 
With the enhanced status of Awka as a state capital since 1991, there has been an associated rise in living standards as well as a boost in the quantity and nature of solid waste generated. The city is presently experiencing various forms of waste management problems. The situation is worse after every rainfall, as the drains are blocked with wastes thereby encouraging urban flooding [1]. There have been extensive studies on the problems of solid waste management in Nigeria, and these include the works of Okpala [2]; Ademoroti and Akpovi [3]; Adedibu and Okekunle [4]; Umeakuka and Mba [5]; Uchegbu [6]; Onwurah et al. [7] and Okonkwo [8, 9]. Among the identified problems of solid waste management are ignorance of the volume and classes of generated waste, inadequacy of the collection system and improper disposal system.

The repeated transfer of solid waste management from one agency to the other has not solved the problem of physical devastation associated with it. This paper therefore, presents a well-articulated plan of the various attributes of the solid waste management system in Awka as the only solution to its efficiency and effectiveness. The rest of the paper consists of study area, methodology of study, findings, recommendations and conclusion.

\section{Study area}

Awka the capital of Anambra State of Nigeria and a pre- colonial city situates on latitude 60025 " $\mathrm{N}$ and longitude $700 \mathrm{E}$. It lies within the rainforest area but is now classified within the Guinea Savannah because of its derived vegetation, as the original vegetation has been removed by man. The mean annual rainfall is about $1524 \mathrm{~mm}$ with a relative humidity of $80 \%$ at dawn. Its location and its climatic characteristic high ambient temperature and rainfall add to the problem of waste management because of rapid rate of putrefaction with its attendant odour. Awka is about $40 \mathrm{~km}$ on the direct route from Onitsha with East-West extension of $8 \mathrm{~km}$ on Enugu- Onitsha express way corridor (Figure 1).

The traditional city has four main quarters containing thirty three villages but as a capital city, now, have an additional eight housing estates and about five residential layouts. The population of Awka from 2006 national census is not available as the National Population Commission is yet to release the figures according to the various communities, seven years after the census. But the figure projected from 1991 census, its unreliability notwithstanding, at the growth rate of $2.79 \%$ is 103,771 for the year ended 2012 The figure is considered unreliable because the state as carved out that year and the bulk of the present population were still at Enugu, the capital of the old Anambra State at the time of the census.

\section{Methodology of study}

The study was based on a research in 2006, Okonkwo and Muoghalu [10], reviewed/ updated in 2012. Data was realized by interview, administration of questionnaire, and measurement and classification of household generated waste. Personal interviews were conducted with successive zonal controllers at the 
Awka zonal office of Anambra State Environmental Protection Agency (ANSEPA), as well as key officers at the Head Quarters of the Agency. Also interviewed are successive Executive Directors and staff of Anambra state Waste Management Authority (ASWAMA). The interviews gathered information on solid management administration such as volume and classes of generated wastes, staff strength and categories, equipment, organized waste dumps, disposal method, constancy of waste removal, disposal sites, other instruments, finance and general problems. Weekly measurement and classification of generated solid wastes were carried out in 600 households purposively selected in the study area. Questionnaire was administered on the selected households, which tapped information mainly on the removal of household generated waste, number and position of available public waste dumps, roads for collector vehicles and availability of disposal vehicles.

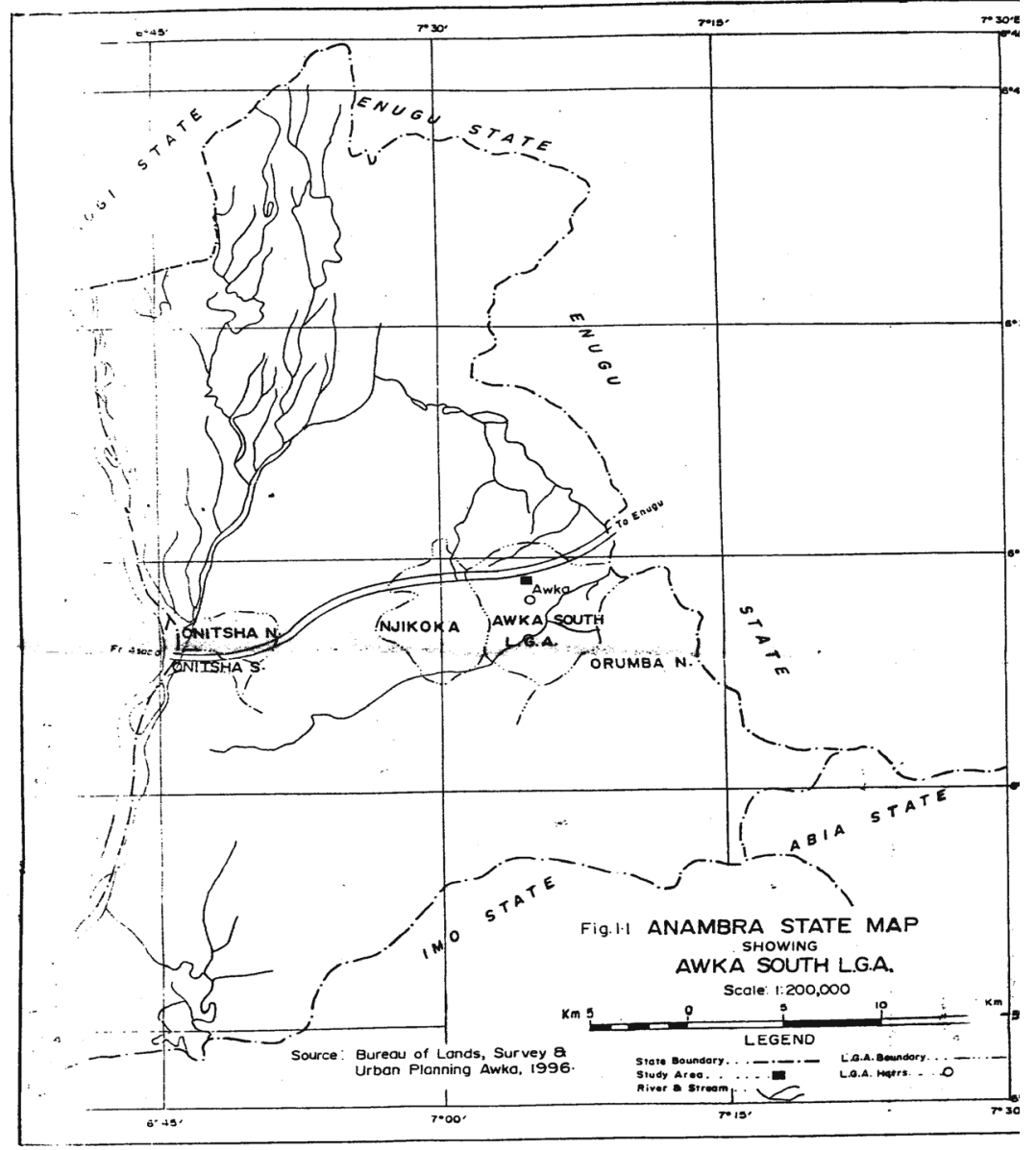

Figure 1 Map showing the study area. 


\section{Findings}

\subsection{Solid waste management authorities in Awka}

The task of refuse collection and disposal is primarily assigned to the Local Government under the Fourth Schedule of the Constitution of the Federal Republic of Nigeria, 1999. The Head of Environmental Health Department of Awka South Local Government affirmed to this but recalled that the Local Government was relieved of this function in Anambra State by the establishment of Anambra State Environmental Sanitation Authority (ASESA) in 1985 and has not been returned to it since then. Then the advent of the Federal Environmental Protection Agency (FEPA) and the guidelines /standards for the operations of the agency in 1991, ushered in the Federal Government directive for every state of the federation to set up its own environmental protection agency. With the Federal Government directive to every state government to set up its own environmental protection agency, Anambra State Environmental Protection Agency (ANSEPA) was established in 1998 to replace ASESA. Thus solid waste management became part of the responsibilities of ANSEPA, until, 2011 when Anambra State Waste Management Authority (ASWAMA) was established to take over the task of waste management in the state. Awka being the capital city is expected to attest to the effectiveness or otherwise of this Authority.

\subsection{Solid waste management in Awka}

Waste management under ASESA was characterized by heaps of waste at undesignated sites, around residential homes and along major streets. Even the well-built, designated public dumpsites were left to accumulate for weeks without evacuation. Anambra State Environmental Protection Agency (ANSEPA) performed its own waste management under the Operations Department with a zonal office also at Awka. Suffice to mention that waste management was only one of the numerous functions of the Agency. Hence, this zonal office handled solid waste management in Awka with a staff strength of eight for both collection and disposal of solid waste from all land uses, namely; residential; commercial; industrial; institutional etc. None of these were skilled, the highest educational qualification being the West African School Certificate (WASC) possessed by two of them, with no form of on-the-job training course(s). The only functional equipment available were; a pail loader, a small bulldozer and one refuse truck. A tractor was later procured for lifting motorized bins, which was introduced in 2005. Interview with the zonal controller, revealed that there was no form of data on the volume of solid waste generated by the various sectors, their characteristics nor the socio-economic characteristics of the generators. The Agency was only evacuating mixed solid wastes whenever and however they can and dumping them at some gully sites. 
A study of the operations of the Anambra State Waste Management Authority (ASWAMA), established in May 2011 revealed a slight improvement from that of ANSEPA. This involves placing of receptacles at strategic places for the collection of waste. The receptacles, which are either big or small, are emptied and evacuated to the final dumpsites by either a chain-up vehicle or a compactor respectively (Figures 2 and 3 ).

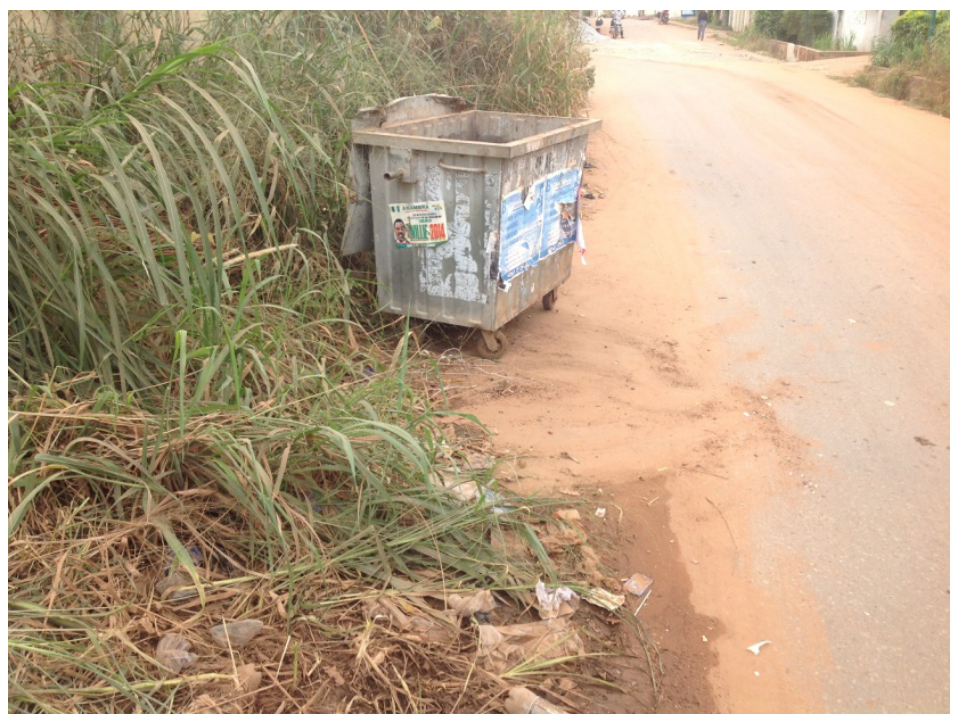

Figure 2: $\quad$ Small receptacle.

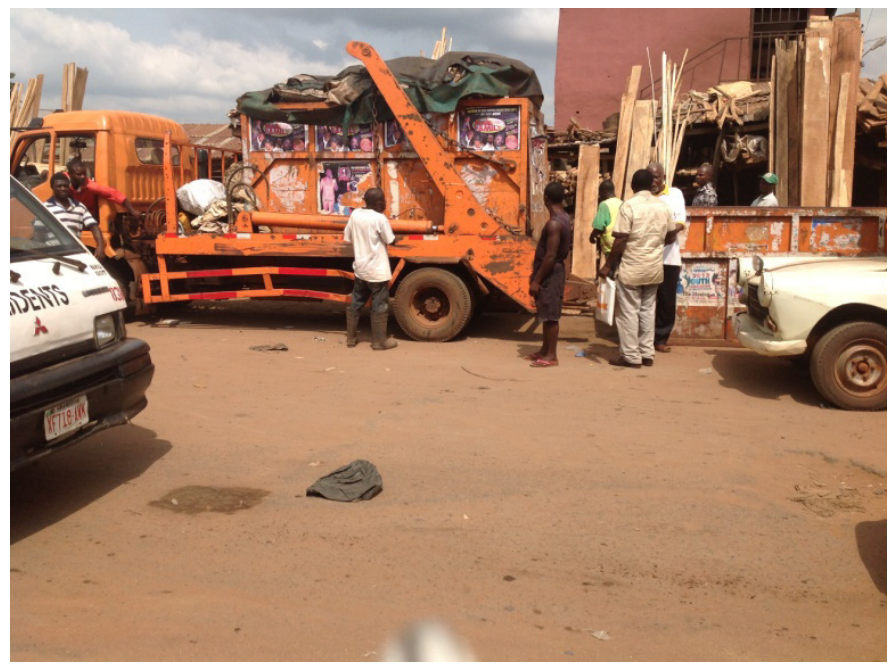

Figure 3: $\quad$ Chain up vehicle with big receptacle. 
The determination of the points for the placement of the receptacles are guided by the seemingly concentration of activities and not any empirical data. The Authority engages street sweepers on major roads in Awka, but the wastes are openly dumped without any form of treatment. The final dumpsite is still a gully erosion site, yet there is a United Nations approved site at nearby Nise, which is not in use. The generated wastes are collected and dumped, not segregated but mixed. And at the dumpsite scavengers are seen scrambling for valuables (Figure 4).

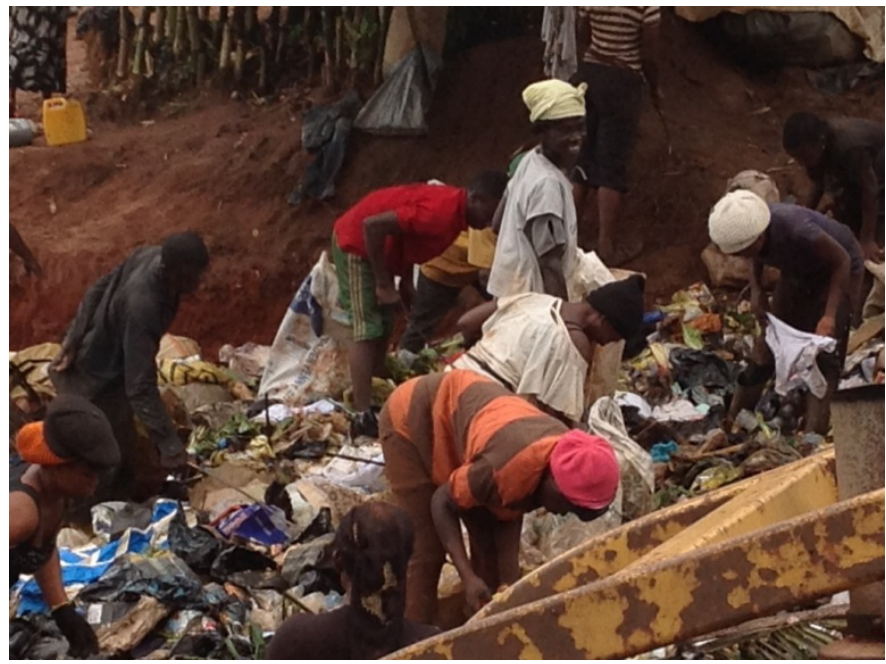

Figure 4: $\quad$ Scavengers at the final dump site.

Though the staff strength is about one hundred and forty, majority are casual (temporal) street sweepers with First School Leaving Certificate (FSLC) and Senior Secondary School Certificate (SSSC). The staff comprises of only one M.Sc. and fifteen B.Sc. graduates and none of these is skilled or a professional in environmental management or waste management. Interview with the staff of ASWAMA revealed that from the inception of the Authority till date no form of training has been organized and undertaken by them. On the issue of finance, the Authority has two sources of funding; government subvention and internally generated revenue (IGR). But this could still be described as one source since the IGR is paid directly into government account and cannot be accessed by the Authority unless through the State Government's disbursement. As such the Authority is not independent and goes through state government bureaucracy for the release of any fund required.

On the issue of volume and classes of solid waste generated, the Authority ventured an estimate of 435 tons of unclassified solid waste daily. But this was based on the number receptacles and on the assumption that they are all evacuated every day. In the calculation the city was divided into eleven zones with the five compactor vehicles covering five zones while the six chain-up 
vehicles serves six zones. It is estimated that each of the 5 compactor vehicles with the capacity of 10 tons would evacuate waste twice daily, which is 20 tons each. It is also believed that the 6 chain-up vehicles make 67 trips, removing between 10 and 15 big receptacles of 5 tons each, every day. Thus, it is estimated that the chain-ups evacuate 335 tons and the compactors evacuate 100 tons of solid waste daily. Yet, still is the fact that the Authority does not evacuate all the receptacles every day. The Authority also affirmed that, even the spread of the receptacles is yet to cover the entire capital city of Awka. The coverage is based on the availability of the receptacles and accessibility for their vehicles and the areas covered by motorable access road are less than $40 \%$ of the capital city. The receptacles are not seen in some motorable parts of the city, such as Ifite area. Therefore, the estimation of the volume of generated waste done by ASWAMA can be described as arbitrary and as such unreliable. Since mixed wastes are being collected the issue of classification is obviously out of it. The characteristics of the generators are also not known since no survey has been conducted to ascertain this.

But from the measurement and classification of household generated waste done by the researcher in 2006, an estimated 140,239 $\mathrm{kg}$ that is, 140 metric tonnes was recorded. This culminated into six classes of waste namely; food/ residue, nylon/ plastic, metal/ bottle, paper, leaves/ garden and others unclassified (Table 1).

Table 1: Estimation of Daily Household Solid Waste Generation in Awka.

\begin{tabular}{|l|c|c|}
\hline \multicolumn{1}{|c|}{ Component } & $\begin{array}{c}\text { Waste Estimation } \\
(\mathrm{kg})\end{array}$ & $\begin{array}{c}\text { Percent } \\
(\mathbf{\%})\end{array}$ \\
\hline Food Residue & 57809.3 & 41.2 \\
\hline Nylon/ Plastics & 15606.7 & 11.1 \\
\hline Metal/ Bottles & 8367.4 & 6.0 \\
\hline Paper & 7982.0 & 5.7 \\
\hline Leaves & 21418.3 & 15.3 \\
\hline Unclassified & 29056.1 & 20.7 \\
\hline Total & $\mathbf{1 4 0 , 2 3 9 . 8}$ & $\mathbf{1 0 0}$ \\
\hline
\end{tabular}

Source: Computed from Author's Field work (2006).

\section{Recommendations: policy and planning implications}

The findings of this research revealed that waste management in Awka has been handled by many agencies yet the method has not improved and as such, yet to achieve the desired results. The 4Rs of reduce; reuse; recycle and recovery are not obtainable in Awka since wastes are still dumped mixed and at unplanned sites. The volume of generated waste are not, authoritatively, known but the researcher's survey revealed six classes of household solid waste. These components can either be composted or recycled or reused thereby reducing the 
volume of the waste stream to be finally treated and disposed. The major part of the unclassified waste are sand mixed with other wastes. It then means that the food residue, leaves/ garden and unclassified making up more than $70 \%$ of the generated waste could be composted and used in place of chemical fertilizer. Organic manure has a lot of advantages with no negative environmental impact insult. Nylon/ plastics, metal and paper wastes making up more than $22 \%$ of the generated waste should be recycled and reused. Thus, for the capital city of Awka less than $10 \%$ of the household generated waste should be treated and disposed.

This, can generally, be applicable in totality to solid waste management in the capital city, if only, there is a well- articulated plan of the attributes. The known attributes of waste management system are generation, collection, transportation and disposal. These attributes are dependent and interdependent on each other, such that a structure that ensures an efficient and effective method of one affects the other. Once a survey of the generators is conducted to ascertain the socioeconomic characteristics, volume and classes of waste generated, this will in turn affect the collection, transportation and disposal methods. The suitable method of collection should be house-to-house where the various classes of waste should be separated at source and collected differently. The collector vehicles should be specific on the class of waste, which should be directed to the appropriate section of; recycling, reuse, composting and treatment/ disposal. For the commercial, industrial and institutional wastes, the receptacles should also be class specific and collected/ evacuated in the same way too. Even for residential areas that are not yet motorable special arrangement should be made and component specific receptacles placed at reachable distance, with dump guards to ensure compliance. Hence the volume of each class of waste to be revealed by the survey would determine the number of trips to be made by the specific collector vehicles.

In order to achieve compliance, education and awareness campaign should be embarked upon among the populace. This campaign should cover among other things the need to sort generated waste at source as well as the advantages of compost manure and recycled waste. The waste fee collection system should be changed to reflect pay as you generate and incentives given for compliance to sorting at source in different containers. The Waste Management Authority should employ professionals as well as train its staff to be able to handle this improved management system. The Government should facilitate the Waste Management Authority to make it independent by establishing the composting and recycling plants, as well as, stop the importation of fertilizer.

\section{Conclusion}

The importance of a structure ensuring a well-articulated plan of the attributes of solid waste management system has been emphasized in this study. The major problem of waste management system in Awka capital city does not lie with the body but with the system and methods. 
The recommendations of this work, if adhered to, will not only make the practices of the Waste Management Authority efficient and effective but also self-sustenance and independent as it is likely to improve its fund from sales of manure, recovered and recycled materials. When this is achieved, it could then be extended to other parts of the state.

\section{References}

[1] Muoghalu, L.N \& Okonkwo, A.U, Effects of Urban Flooding in Awka, Capital of Anambra State of Nigeria, Environmental Review, 2 (2) 74-81, 1998.

[2] Okpala, D.C.I, Institutional Problems in the Management of Nigeria Urban Environment, Nigeria Institute of Social and Economic Research (NISER), Ibadan, 1986.

[3] Ademoroti, C.M.A. \& Akpovi S.U, Solid Waste Generation by the Urban Poor in Benin City, in P.K. Makinwa and O.A. Ozo (eds). The Urban poor in Nigeria, Ibadan; Evans Brothers (Nigeria) Publishers Ltd, 377-386, 1987.

[4] Adedibu, A. A \& Okekunle, A. A, Issues in the Environmental Sanitation of Lagos Mainland, Nigeria, the Environmentalist, 9 (2) 91-99, 1989.

[5] Umeakuka, J.M. \& Mba, H.C, Solid Waste Management Practices: A Case Study of Anambra State, Journal of the Nigerian Institute of Town Planners, 14-26, October, 1999.

[6] Uchegbu, S.N, Urban Waste Management and Sustainable Development in Nigeria, Environmental Studies and Research Journal 1 (2) 70-81, October 2002.

[7] Onwurah, I.N.E, Ogugua, V.N. \& Otitoju, O.E, Integrated Environmental Biotechnology Oriented Framework for Solid Waste Management and Control in Nigeria' Int. J. Environment and Waste Management, 1 (1) 94-104, 2006.

[8] Okonkwo, A.U, Waste Management and Economic Growth: Classification of Waste a Means of Revenue generation in Awka, Anambra State. Journal of Environmental Research and Polices 5 (4) 8-14, 2010.

[9] Okonkwo, A.U, Perspectives on Sustainable Waste Management: A Study of Process and Institutional Building in Awka, Anambra State, Developing a Friendly and Sustainable Environment: The Global Challenge, EBAN, 29-52, 2012.

[10] Okonkwo, A.U \& Muoghalu, L.N, The Problems of Solid Waste Generation and Management in Awka, Anambra State: The Role of Women. Unpublished Ph.D Dissertation, Dept of Environmental Management, Nnamdi Azikiwe University, Awka, 2009.

[11] Anambra State Government, Environmental Sanitation Law, Official Gazette cap.44, 1595-1608, 1987. 